\title{
In Vitro Evaluation of Some Selected Fungicides Against Leaf Spot Pathogen (Pestalotiopsis sp.) on Oil Palm Seedlings
}

${ }^{1}$ E. Lekete, ${ }^{2}$ E. A. Osekre, ${ }^{2}$ E. M. K. Sosu, ${ }^{3}$ M. M.Apetorgbor

1, 2CSIR-Oil Palm Research Institute, Box 74, Kade

${ }^{2}$ Crops and Soil Science Department, KNUST, Kumasi

${ }^{3}$ CSIR- Forestry Ressearch Institute of Ghana, UP63, KNUST, Kumasi

\begin{abstract}
.
Leaf spots on oil palm (Elaeis guineensis Jacq.) caused by Pestalotiopsis sp, was found in nursery on oil palm seedlings in Ghana. The objective of this study was to develop appropriate management strategies by evaluating efficacy of Suncozeb 80WP, Hepridion and Goldazim 500Sc fungicides against Pestalotiopsis sp. The recommended fungicides were tested at 25,50,75, 100 and $125 \mathrm{ppm}$. Bioassay showed that all the fungicides at all concentrations inhibited the growth of the pathogen and their effects differed significantly at $1 \%(0.01)$. No fungal growth (mycelia) was observed in Carbendazim $500 \mathrm{SC}$ at the concentrations of $100 \mathrm{ppm}$. All three fungicides exhibited higher efficacy at higher concentrations. Of the all the three fungicides tested, Carbendazim 500SC was able to effect varying degrees of suppression of the mycelial growth of the leafspot pathogen. It can be concluded that Carbendazim $500 \mathrm{SC}$ was the most effective against growth of Pestalotiopsis sp. in vitro and therefore should be tested under field condition (in vivo).
\end{abstract}

Keywords: Leaf spot, Pestalotiopsis, fungicide, inhibition, bioassay 
